\title{
ANÁLISE TEÓRICA DO HOMICÍDIO JUVENIL MASCULINO: CATEGORIZAÇÃO DA VIOLÊNCIA E SUA ARTICULAÇÃO MULTIESCALAR NO BRASIL URBANO
}

\section{THEORETICAL ANALYSIS OF THE MALE YOUTH HOMICIDE: CATEGORIZATION OF VIOLENCE AND ITS MULTISCALE JOINT IN URBAN BRAZIL}

\section{Alex Manetta ${ }^{1}$}

\begin{abstract}
Resumo
Esse artigo se compõe de um estudo sobre as relações entre as manifestações locais do homicídio juvenil masculino e a expansão de fenômenos globais. A metodologia utilizada consiste em qualificar as manifestações predominantes do homicídio como uma categoria particular de violência direta, que se expressa através de uma interação de tipo triangular com outras duas categorias: a violência estrutural e a violência cultural. Partindo dessa distinção categórica se avança em direção ao reconhecimento de uma articulação de caráter multe-escalar, segundo a qual cada uma das três categorias de violência - descritas por Galtung (1999) - pode ser melhor apreendida através de escalas espaciais específicas. Como resultado vislumbra-se uma contribuição à análise teórica e conceitual da violência homicida no Brasil urbano, salientando que se trata de um fenômeno que não deve ser diretamente relacionado aos contextos locais de relativa pobreza, já que deriva de relações muito mais amplas e complexas. Como conclusão destaca-se que a interpretação a respeito do processo de elevação da incidência do homicídio entre homens jovens deve ser buscada exatamente na associação entre dinâmicas espacialmente localizadas e elementos estruturais do sistema capitalista contemporâneo.
\end{abstract}

Palavras-chave: homicídio juvenil masculino; violência; manifestações locais; fenômenos globais.

\section{Abstract}

This article consists of a study based on the relationship between the local manifestations of the male youth homicide and the expansion of global phenomena. The methodology used is to qualify the prevailing murder manifestations as a particular category of direct violence, which is expressed through a triangular type of interaction with the other two categories: structural violence and cultural violence. From this categorical distinction it is progressing toward recognition of a multiscale articulation, according to which each one of the three categories of violence - described by Galtung (1999) - can be best apprehended through specific spatial scales. As a result we have a contribution to the theoretical and conceptual analysis of homicidal violence in urban Brazil, highlighting that it is a phenomenon that should not be directly related to local contexts of relative poverty, since it derives from much broader and complex relationships. In conclusion it is emphasized that the interpretation about the process of rising of the incidence of male youth homicide is to be found precisely in the association between spatially localized dynamics and structural elements of the contemporary capitalist system.

Keywords: male juvenile homicide; violence; local manifestations; global phenomena.

\footnotetext{
${ }^{1}$ Bacharel em Geografia (IG/Unicamp), Mestre e Doutor em Demografia (IFCH/Unicamp) com pós-doutorado na Escola Nacional de Ciências Estatísticas (ENCE/IBGE). Função e afiliação: Professor Pesquisador afiliado à Área Acadêmica de Sociología y Demografía do Instituto de Ciencias Sociales y Humanidades da Universidad Autónoma del Estado de Hidalgo (UAEH/México). E-mail: alexmanetta@hotmail.com
} 


\section{INTRODUÇÃO}

Muito comia a guerra, muito a guerra enriquecia. É a guerra aquele monstro que primeiro que devore os homens Ihes despeja os bolsos, um por um, moeda atrás de moeda, para que nada se perca e tudo se transforme, como é lei primária da natureza... E quando está saciada de manjares, quando já regurgita de farta, continua no jeito repetido de dedos hábeis, tirando sempre do mesmo lado, metendo sempre no mesmo bolso (SARAMAGO, 1980: 178).

A sociedade brasileira se desenvolveu em um sistema no qual o uso da violência foi, e continua sendo, recurso frequentemente adotado como forma de resolução de conflitos (VELHO, 2000). Sugere-se, no entanto, que o panorama atual apresenta novidades, ou seja, características peculiares reveladas pelo agravo do homicídio entre homens jovens (com idades entre 15 e 24 anos).

No Brasil o crescimento recente das taxas de homicídio afetou particularmente o segmento juvenil masculino (WAISELFIZS, 2015a; 2014a e 2013), tanto nas capitais e regiões metropolitanas quanto no interior do país (WAISELFIZS, 2010), em um contexto no qual predominaram os crimes cometidos em locais públicos, entre pessoas que não eram íntimas e nem mesmo conhecidas, com a utilização crescente de armas de fogo (ZALUAR, 2007; WAISELFIZS, 2015b).

Disseminaram-se pelo país elevados riscos de homicídio entre homens jovens, sobretudo entre residentes de periferias urbanas (ADORNO, 2002; WAISELFIZS, 2011), cenário no qual ganham destaque duas das seis características da mortalidade violenta no Brasil, descritas por Minayo (2009): a concentração dos homicídios por sexo, por idade e por local de residência; e a prevalência, como meio, da utilização de armas de fogo.

O Gráfico 1 ilustra como progrediram as taxas² de homicídio da população total brasileira, que passaram de 11,7 para 28,6 (homicídios para cada 100 mil pessoas) entre os anos 1980 e 2013, correspondendo a uma variação próxima aos 144 (\%) no período. Já as taxas de homicídio da população total masculina evoluíram de 21,2 para 52,9 (homicídios para cada 100 mil pessoas), em uma variação de quase 150 (\%) entre os anos 1980 e 2013. No que se refere à população juvenil masculina (com idades entre 15 e 24 anos), as taxas de vitimização por homicídio aumentaram de 31,6 para 114 (homicídios para cada 100 mil pessoas) no período (1980-2013), representando uma variação superior aos 260 (\%). No que diz respeito à evolução da incidência de homicídio entre

\footnotetext{
${ }^{2}$ Nota técnica: para o cálculo das taxas de homicídio foi adotada a classificação proposta por Lozada et. al (2009), segundo a qual os homicídios correspondem às mortes classificadas nas categorias entre E960/E978 (CID-9) (1979-1995) e entre X85/Y09 e Y35/Y36 (CID-10) (1996-2010). Foram utilizadas as estatística vitais contidas no Sistema de Informações sobre Mortalidade do Ministério da Saúde (SIM/MS).
} 
homens jovens tendo como meio a utilização de armas de fogo, nota-se um crescimento ainda mais significativo, já que evoluiu de uma taxa de 15,3 a 84,9 (homicídios para cada 100 mil pessoas) entre os anos de 1980 e 2013, apresentando uma variação de aproximadamente 453 (\%).

Gráfico 1. Brasil - taxas anuais de vitimização por homicídio para a população total, para a população total masculina, para a população juvenil masculina (15-24 anos) e para população juvenil masculina com a utilização de armas de fogo (15-24 anos) (A. F.) (1980-2013).

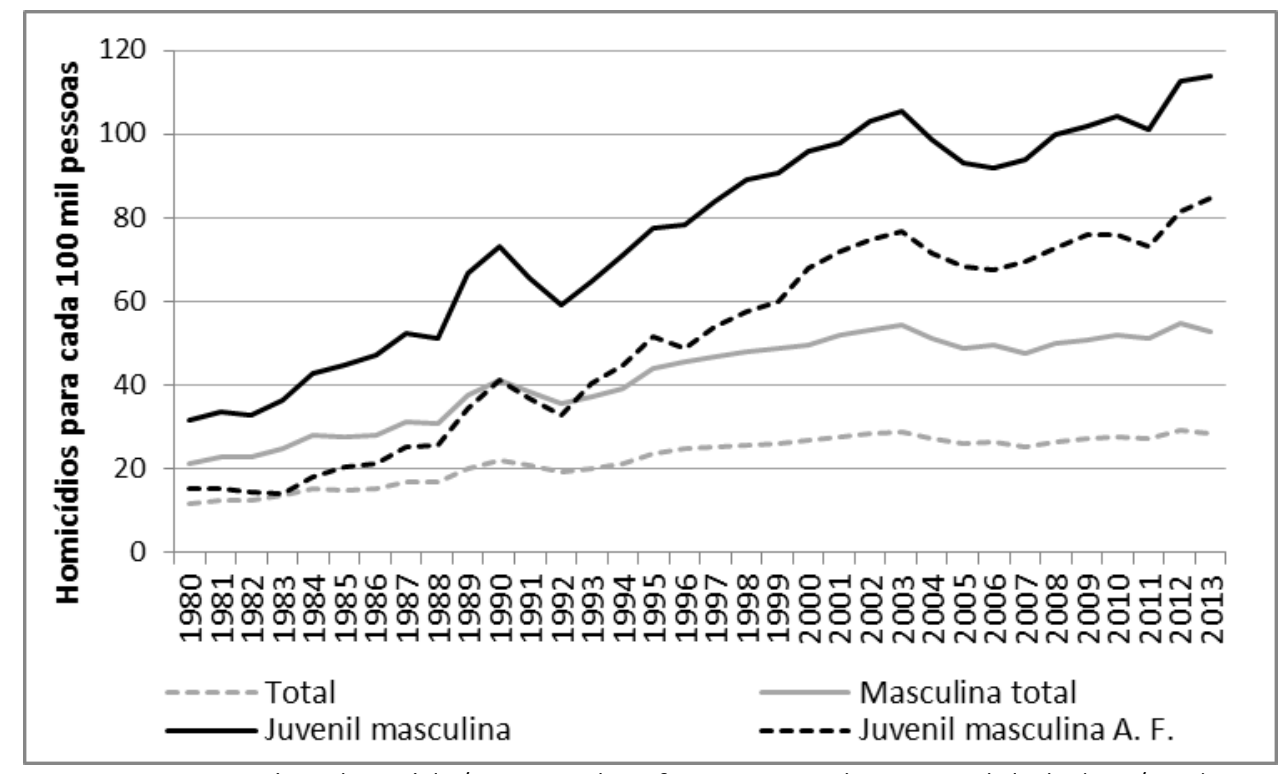

Fonte: Ministério da Saúde/Sistema de Informações sobre Mortalidade (MS/SIM).

Resumidamente o Gráfico 1 demonstra como as taxas de homicídio para a população total brasileira cresceram no período entre 1980 e 2013, e como esse crescimento esteve concentrado na população masculina. Para uma melhor noção a respeito da concentração desse tipo de evento entre homens pode ser utilizado o indicador razão de sexo, que passou de 9,1 para 10,8 (homicídios de homens para cada mulher assassinada) entre os anos 1980 e 2013, segundo os registros de estatísticas vitais do Sistema de Informações sobre Mortalidade do Ministério da Saúde (SIM/MS).

A concentração dos assassinatos em uma população específica se torna ainda mais evidente quando à variável sexo se agrega a variável idade, já que as taxas de homicídio para a população juvenil masculina foram as que mais cresceram no período (1980-2013). A semelhança entre as curvas das taxas de homicídio juvenil masculino e das taxas de homicídio juvenil masculino com a utilização de armas de fogo (A. F.) demonstra como a vitimização de homens jovens por assassinato está intimamente relacionada à disponibilidade e ao uso letal desse tipo de instrumento no Brasil contemporâneo (Gráfico 1). 
Em números absolutos essa evolução significa que passamos de um contexto no qual foram registrados 13.911 homicídios (ano de 1980), dos quais 12.535 foram de pessoas do sexo masculino e 3.913 de homens jovens, para um contexto (ano de 2013) no qual foram registrados 57.396 homicídios, dos quais 52.522 foram de pessoas do sexo masculino e 19.773 de homens jovens, em acordo com os registros de estatísticas vitais do Sistema de Informações sobre Mortalidade do Ministério da Saúde (SIM/MS) (Gráfico 2).

Gráfico 2. Brasil - volume total anual de homicídios, de homicídios de homens e de homicídios de homens jovens (15-24 anos) (1980-2013).

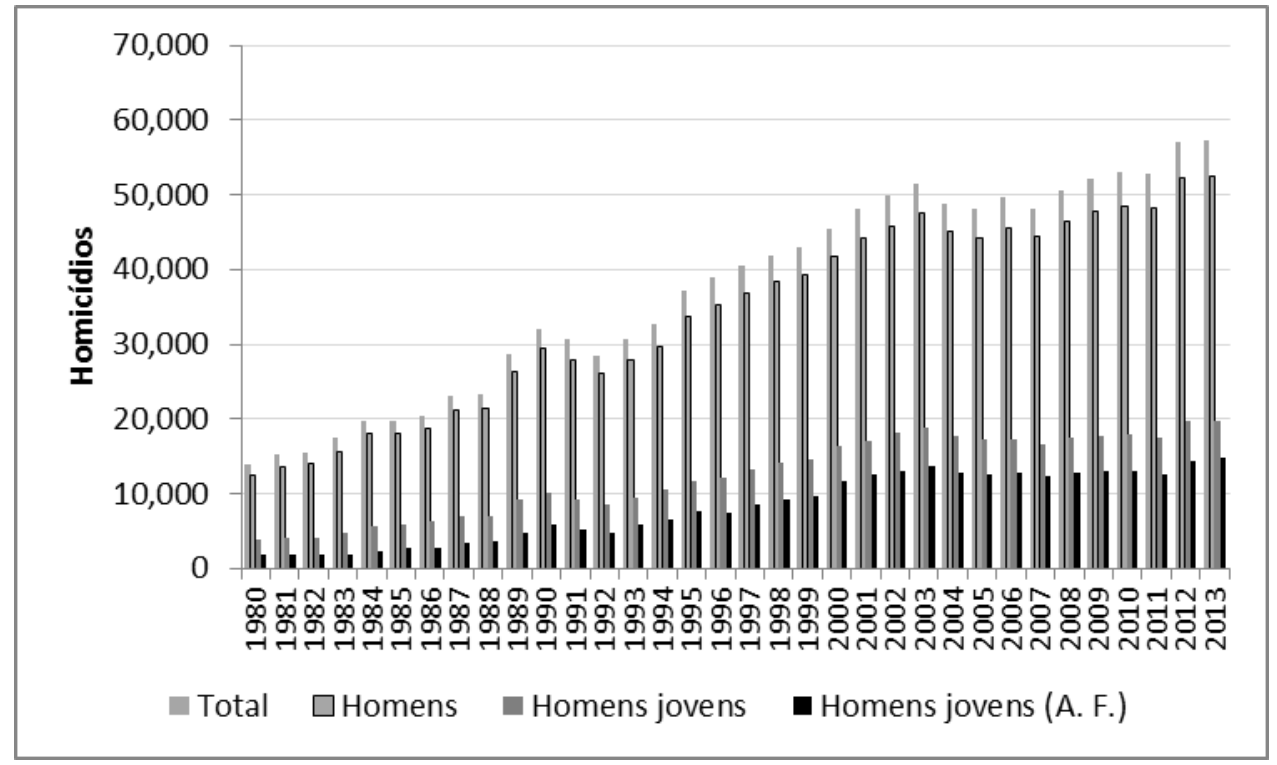

Fonte: Ministério da Saúde/Sistema de Informações sobre Mortalidade (MS/SIM).

Em termos demográficos os homicídios não só reduzem a esperança de vida e influem na inflexão precoce da razão de sexo da população brasileira (Manetta e Alves, 2015) como interferem também na dinâmica familiar ao interromperem o ciclo de vida de homens e de mulheres, figurando como um grave problema social e de saúde pública. A vitimização de significativos volumes de jovens constitui também um grave problema econômico que influi enormemente nas condições de desenvolvimento da sociedade brasileira (Cerqueira e Moura, 2013).

Embora esse artigo trate a violência homicida de forma teórica e conceitual, utilizando como referência dados e estudos que consideram a questão em nível nacional, salienta-se que esse é um fenômeno que não se manifesta de maneira homogênea no território, sendo que se apresenta com mais intensidade nas periferias das grandes cidades e regiões metropolitanas. Nos últimos anos, entretanto, foram registrados crescimentos significativos das taxas de homicídio em 
municípios interioranos e também em algumas capitais, notadamente no nordeste brasileiro, onde em décadas anteriores essas taxas não eram tão intensas, como Maceió (AL), Salvador (BA), João Pessoa (PB), Recife (PE), Vitória (ES), Manaus (AM), São Luis (MA), Natal (RN) e Fortaleza (CE). Por outro lado, em capitais como São Paulo (SP) e Rio de Janeiro (RJ), onde nos anos 1990 e início dos anos 2000 foram registradas as mais elevadas taxas, se observaram significativos decréscimos (WAISELFISZ, 2014b).

A magnitude desse problema, sua disseminação pelo território e seu estabelecimento como um problema crônico são fatos que justificam o presente estudo, pois, somente através de um entendimento complexo e abrangente da realidade contemporânea é que será possível ampliar as possibilidades de formulação estratégica e de gerenciamento de ações voltadas à mitigação desse desastre que há décadas assola a sociedade brasileira.

\section{PROBLEMATIZAÇÃO}

A persistência das desigualdades sociais (WAISELFISZ, 2008; AIDAR, 2003; SZWARCWALD et al., 1999; BERCOVICH et al., 1998), da pobreza e do desemprego (CANIATO, 2008; OLIVEIRA e PINTO, 2001; HIRATA, 2001) são aspectos avaliados como fatores básicos desencadeadores de elevados índices de criminalidade, constituindo campos altamente propícios ao desenvolvimento da violência juvenil homicida. No entanto, existem controvérsias com relação às causas imediatas do crescimento de um tipo de violência criminal, armada, juvenil e homicida, predominante hoje no Brasil, já que as evidências empíricas disponíveis não oferecem respostas definitivas às hipóteses de que o desemprego, a pobreza ou as desigualdades sejam fatores relacionados em nível causal a esse fenômeno (DELLASOPPA et al., 1999).

Dentre as poucas generalizações que podem ser feitas sobre as manifestações recentes da violência armada no mundo, se destacada àquela que vincula sua expansão com a disseminação de um tipo de criminalidade urbana cuja dinâmica extrapola limites locais, regionais ou mesmo nacionais (GIIS, 2006). No Brasil, a vinculação contemporânea entre as formas predominantes do homicídio juvenil masculino e as dinâmicas do tráfico de drogas revela conexões entre circuitos locais e redes ampliadas do ilícito, evidenciando o fato de que os investimentos fundamentais a uma dinâmica transnacional do crime, na forma de dinheiro, de informação, de armas e de drogas, não podem ser provenientes das localidades onde a violência homicida se mostra de maneira mais evidente (SOARES, 2006). 
Trata-se de um fenômeno que deve ser discutido na perspectiva da complexidade, averiguando-se como a escassez de melhores oportunidades de inserção social e econômica para homens jovens está relacionada aos mecanismos e aos fluxos constituintes de economias transnacionais do ilícito (ZALUAR, 2007). Faz-se menção à disseminação global das oportunidades de integração perversa, fenômeno cuja referência está associada às formas de trabalho e de socialização praticadas através do crime (CASTELLS, 2003).

A ideia da constituição do crime como um mercado laboral alternativo foi reafirmada no Seminário sobre Crianças Afetadas pela Violência Armada Organizada (2002), quando os participantes concordaram sobre uma definição de trabalho para jovens que atuam nas quadrilhas de traficantes ou em outros grupos armados do Brasil e de outras partes do mundo (DOWDNEY, 2005). A produção e a comercialização de drogas ilícitas representam os principais setores do crime organizado transnacional e constituem a coluna vertebral da economia em inúmeras localidades e até mesmo em algumas nações, promovendo alternativas de trabalho e de geração de renda para significativos volumes de pessoas ao redor do mundo (VEEN, 1999).

Considerando o potencial específico de integração de cada bairro, de cada cidade ou região a qualquer setor de atividade econômica, como as possibilidades dadas por suas respectivas peculiaridades, assume-se que na economia do crime não poderia ser diferente, de modo que tende a se expandir onde as condições se mostram minimamente propícias. Seguindo essa linha de raciocínio, o processo de disseminação de oportunidades de integração ao crime depende da articulação entre dinâmicas vigentes em diferentes escalas espaciais, através da conexão entre atividades variadas, espalhadas por diversos países e regiões, constituindo extensos circuitos espaciais de produção e de circulação que incluem complexas divisões sociais do trabalho.

Nesse sentido, as localidades e regiões marcadas pela precariedade estrutural, por elevados índices de desigualdade e pela relativa incapacidade de governança, no Brasil, tendem a estarem aptas como abrigos de atividades ilícitas específicas, como o tráfico varejista de drogas. De maneira correlata a população local, especialmente a população juvenil masculina, figura como mão-de-obra potencialmente barata e relativamente descartável, comumente empregada como recurso na manutenção de atividades criminalizadas (BATISTA, 2003; SOARES, 2006).

Reconhece-se a importância da linha de pensamento que mantém como marco teórico as relações local/global, vislumbradas através de processos cuja extensão e intensidade se fazem sentir tanto por fenômenos vigentes em escalas espaciais ampliadas quanto por manifestações particulares observadas em localidades específicas. 


\section{OBJETIVOS}

Esse artigo traz como objetivo geral realçar teoricamente as relações entre as manifestações locais do homicídio juvenil masculino e a expansão de fenômenos globais, com destaque para processos como: a unificação dos sistemas técnicos, dos circuitos espaciais de produção, de circulação e de consumo; a expansão de uma racionalidade econômica dominante e a emergência de problemas vigentes em escala global, o que inclui a disseminação transnacional do crime e das manifestações predominantes da violência homicida.

Como objetivos específicos se propõem: qualificar o homicídio juvenil masculino como uma categoria específica de violência direta que se manifesta de maneira articulada a outras duas categorias (violência estrutural e violência cultural) e; atribuir escalas espaciais privilegiadas para a apreensão das expressões de cada categoria de violência mencionada, como possibilidade de contribuição à análise conceitual das formas predominantes do homicídio entre homens jovens no Brasil urbano contemporâneo.

\section{METODOLOGIA}

A metodologia utilizada consiste em qualificar as manifestações predominantes do homicídio como uma categoria particular de violência direta, que se expressa através de uma interação de tipo triangular com outras duas categorias: a violência estrutural e a violência cultural. Partindo dessa distinção categórica se avança em direção ao reconhecimento de uma articulação de caráter multe-escalar, segundo a qual cada uma das três categorias de violência - descritas por Galtung (1999) - pode ser apreendida através de escalas espaciais privilegiadas.

\section{RELAÇÕES LOCAL/GLOBAL E HOMICÍDIO JUVENIL MASCULINO NO BRASIL URBANO}

Desde o último quarto do Século XX especialistas de variadas formações, dentre eles economistas, sociólogos, geógrafos e filósofos, aplicaram seus esforços sobre tentativas de elucidação de uma tendência relativamente recente através da qual se estabeleceram consideráveis mudanças nas dimensões das mais relevantes esferas das relações sociais, culturais, políticas e econômicas, cujas escalas de organização revelam a passagem de um sistema de ordem internacional para um sistema de ordem global (BENKO, 2001). Faz-se referência a importantes mutações geopolíticas nas condições de produção, de circulação, de competição e de interdependência através das quais têm sido fomentadas mais intensas trocas de informações, de 
capitais, de bens, de serviços e de pessoas entre as diferentes partes do globo (BENKO e PECQUEUR, 2001).

Essa reestruturação do sistema capitalista, cuja lógica abarca o rigor da competitividade econômica, tem sido responsabilizada por uma parte substancial das mais recentes facetas do sofrimento humano (CASTELLS, 2003), em um momento no qual são reveladas correspondências entre a constituição de uma economia tornada global e a percepção de um estado de crise igualmente globalizado (SANTOS, 1988: 17).

As evidências dessa crise se fazem sentir tanto por meio de fenômenos globais quanto através de manifestações particulares, localizadas em países, regiões e momentos específicos (SANTOS, 2000), conforme evidenciam as imensas disparidades regionais observadas no fenômeno qualificado como 'redução da pobreza em nível mundial', supostamente ocorrido durante os anos 1990. No decorrer desse processo de ordem global, não obstante, foram observadas manifestações particulares extremamente contraditórias, referentes aos enormes retrocessos sociais e econômicos vislumbrados em extensas e populosas regiões do planeta (PNUD, 2005).

Aproximando-se ainda mais do temário da crise atual Lopes et al. (2010: 11) afirmam que os maiores desafios a serem enfrentados hoje são de ordem sistêmica, se tratando em última instância do enfrentamento de uma crise civilizatória, cujas variadas dimensões - social, econômica, política, ética e ambiental - se tornam cada vez mais evidentes.

Em um momento caracterizado pela crise permanente do sistema são observadas desigualdades extremas na apropriação dos ganhos obtidos através de circuitos globalizados de produção, de circulação e de consumo, e são reconhecidos os papéis avassaladores do sistema financeiro e da permissividade de comportamento dos agentes hegemônicos da política, da cultura e da economia, cuja atuação tem levado - sem contrapartidas - ao aprofundamento da crise (SANTOS, 2000).

Se por razões estruturais o capital financeiro dos mais poderosos investidores tende a crescer mais rápido que o capital do restante dos agentes sociais, a desigualdade entre riqueza e pobreza tende também a aumentar, em um processo que adquiri proporções sem precedentes e que deve resultar em uma divergência radical na distribuição dos recursos econômicos - no mundo - em um futuro relativamente próximo (PIKETTY, 2013). Esse aumento das disparidades quanto ao acesso aos benefícios gerados pela economia global apresenta como uma de suas consequências o reforço de processos como aqueles que excluem extensos segmentos da população mundial dos resultados provenientes de esforços coletivos (OLIVEIRA e PINTO, 2001). 
Dentre os diversos mecanismos capazes de atirar pessoas - e até mesmo territórios inteiros - em situações de exclusão, se destaca o processo de privação ao trabalho formal, remunerado e estável no contexto do capitalismo (CASTELLS, 2003). Em nível mundial a dinâmica econômica resulta em importantes privações às possibilidades de inclusão laboral, fato com implicações nas condições de sobrevivência para amplas parcelas da população (CANIATO, 2008), configurando-se uma tendência de precarização do trabalho como profunda expressão da crise global contemporânea (ANTUNES, 2007).

Os efeitos da globalização sobre a estrutura social, ao ocorrerem de modo contraditório e heterogêneo, desenvolvem a interdependência, a integração e a dinamização entre vários setores econômicos, entre diversas localidades e entre distintos segmentos da população. Ao mesmo tempo são desenvolvidas as desigualdades, as tensões e os antagonismos característicos da sociedade atual. Nesse cenário são multiplicadas as possibilidades de associação, organizadas conflituosamente em torno de interesses divergentes, tornando complexas as questões sociais, o que não exclui os comportamentos relativos à criminalidade e à violência urbana (SANTOS, 1999).

Para além da exclusão de extensos segmentos da população mundial, com relação às possibilidades de trabalho formal, remunerado e estável, o processo de precarização do trabalho evidencia a expansão de oportunidades de inclusão precária e informal, dentre as quais são destacadas as possibilidades de integração através do crime, como tendência vigente no período contemporâneo.

Em acordo com Sachs (1998) vivenciamos hoje um processo global de unificação dos problemas, em um cenário tornado crítico também para os países capitalistas centrais. Mas se nos países do norte global podem ainda ser encontrados resquícios do estado de bem-estar social, nos outros países os trabalhadores estão frequentemente oscilando entre a busca 'quase inglória' do emprego e o aceite de 'qualquer labor', com uma nítida ampliação das modalidades informais de trabalho (ANTUNES, 2007).

Reconhece-se a relevância assumida pelas formas de trabalho informal no Brasil, ao se constituírem como caminhos para a integração socioeconômica, representando significativa expressão na formação de renda para diversos segmentos sociais e como parte integrante do processo global de reestruturação capitalista (RIBEIRO, 2000), contexto no qual o mercado convencional convive com um extenso mercado clandestino, ao se apresentarem profundamente relacionados, sobretudo em situações aprofundadas de crise e de exclusão (COCCO, 2002). 
A noção de exclusão, apesar de suas ambiguidades, recorta uma problemática emergente e em permanentemente mudança, caracterizada tanto por privações e constrangimentos quanto por alternativas de comportamento (OLIVEIRA e PINTO, 2001). A ideia de exclusão não deve, portanto, ser entendida de maneira literal, mas sim como uma porta que se fecha para uma gama de relações e não para outras. Assim, através de relações de conexão, de submissão, de interação ou de interdependência, a noção de exclusão admite tanto variados tipos de restrições quanto emergentes formas de integração (DUFFIELD, 2001: 5), em associações frequentes entre o formal e o informal, entre o lícito e o ilícito (VEGA e KRUIJT, 2007).

Por isso, simultaneamente ao processo de exclusão relativo às (im)possibilidades de trabalho digno e de obtenção de renda nos setores formais da economia globalizada, admite-se a vigência de processos de integração através de setores econômicos clandestinos, como alternativas de inserção aos fluxos gerados pela economia global. Dentre as formas não convencionais de inserção aos fluxos da economia globalizada, para além da inclusão em setores informais da economia urbana (SANTOS, 1979), salienta-se a atenção ao processo específico de integração ao crime.

A emergência de amplos setores clandestinos na economia global, dentre eles, particularmente, a economia do crime, está associada não somente aos limites da inclusão de mais extensos segmentos da população aos circuitos da economia formal (DUFFIELD, 2001), já que também apresenta vínculos com as restrições colocadas por sistemas normativos nacionais e internacionais, de modo que se torna imprescindível designar o crime segundo as normas legais vigentes. Dentro dessa perspectiva os Estados e as organizações supranacionais mantêm papéis fundamentais na configuração do fenômeno criminal de ordem transnacional, uma vez que são os agentes privilegiados na definição das proibições, das restrições e das sanções em voga (CAMPOS e VALENTE, 2012).

No Brasil reiteradamente o Estado tem tratado o enfrentamento da violência como uma questão pura e simples de maior rigor punitivo. Várias são as leis editadas desde os anos 1990 que demonstram a utilização desenfreada do direito penal como possibilidade de contenção da violência (CARVALHO, 1996). Entretanto, como afirma o jurista Alberto Silva Franco, o Direito Penal possui inúmeras funções, dentre as quais não figura a resolução de problemas sociais. Partindo desse ponto de vista se concebe que a transferência de responsabilidades sociais à área de atuação legislativa, como no caso de um suposto controle da violência, tenderia a péssimos resultados (COSTA, 2007). 
A criminalização e a consequente punição aos atos de caráter ilícito, como expressões do conflito estabelecido entre interesses divergentes, contraditoriamente representam importantes fatores na constituição de setores ilegais cada vez mais complexos, mais eficientes e mais lucrativos. A repressão, ao induzir à escassez, induz também à inflação nos preços das mercadorias ilegais, gerando grandes expectativas no que diz respeito ao investimento em negócios criminalizados (VEEN, 1999).

O risco da atividade ilegal, que passa pelo risco de punição, pelas chances de perda da mercadoria ou, em casos extremos, pelo risco de perda da própria vida, atua como fator de maisvalia agregada ao produto ilícito. É evidente que a mercadoria, para se deslocar, deve aumentar de preço durante o percurso. Daí em certos lugares o preço elevado de mercadorias raras que se deslocam por longos trajetos. É preciso que a mercadoria que chega ao consumidor final se valorize de tal maneira que possa pagar, além das despesas imprevistas, o preço de compra mais o preço do transporte e mais ainda o lucro com que o mercador está a contar, pois, "não sendo assim, para que serve arriscar seu dinheiro e o seu trabalho?" (BRAUDEL, 1985: 147-148).

O que dizer então do mercado das drogas e de outras mercadorias ilícitas? Já que ao custo da mercadoria são agregados, além dos custos da produção e do transporte, os custos dos riscos de punição e de perda da mercadoria, mais o custo da corrupção. Dentro desses princípios básicos do capitalismo mercantil, enquanto os governos realçam seus esforços na repressão à indústria da droga, os empresários do crime reorganizam suas atividades em níveis cada vez mais complexos e mais lucrativos.

Em acordo com esses fundamentos a chamada guerra contra as drogas (CAMPOS e VALENTE, 2012; BALTAZAR JUNIOR, 2008) não poderia, assim, por meio da repressão, ser vencida, pois, enquanto houver demanda haverá oferta e assim como os indivíduos se tornam adictos em relação ao consumo de drogas ilícitas as sociedades em que eles vivem se tornam dependentes do dinheiro gerado pelo seu mercado correlato (VEEN, 1999).

As causas do vício em drogas têm sido atribuídas especialmente aos danos psicológicos infligidos às pessoas pela vida cotidiana na sociedade contemporânea (BATISTA, 2003). Seu consumo constante está ligado aos atuais estilos de vida, aos elevados níveis de estresse, de ansiedade e de baixa autoestima, além da susceptibilidade à pressão social imposta pela competitividade (SOUZA et al., 2005; SASSEN, 1991). Em um futuro previsível não seria de se estranhar, portanto, uma demanda maciça por drogas, a despeito dos mecanismos de repressão 
existentes, quando deverão ser encontradas as formas de corresponder a essa procura transformando-a sempre em negócio lucrativo (CASTELLS, 2003: 217-218).

Salienta-se que o jogo de trocas comerciais estabelecido pela relação entre oferta e procura por mercadorias ilícitas não constitui fenômeno recente. No entanto, a configuração atual propicia a emergência de formas inovadoras do crime, tornando evidente a expansão de estratégias empresariais nas atividades ilícitas. Por isso, no âmbito da criminologia, faz-se referência tanto ao paradigma da rede quanto ao paradigma empresarial como etapas particulares de evolução das organizações criminosas (BALTAZAR JUNIOR, 2008).

No caso específico do narcotráfico a divisão do trabalho tende a concentrar a produção em territórios nos quais se detém um relativo controle do meio institucional, via corrupção, extorsão, terrorismo e impunidade. Já a venda da produção está preferencialmente voltada para mercados caracterizados por elevados níveis socioeconômicos, como Europa, Japão e EUA, onde se podem obter maiores lucros com a mercadoria ilegal (CASTELLS, 2003).

Mercados menos valorizados, porém, extensos, conforme aqueles representados pelos consumidores residentes em grandes cidades e regiões metropolitanas brasileiras, movimentam também importantes montantes em capitais e mercadorias, empregando não desprezíveis contingentes de mão-de-obra. Couto (2012) oferece uma descrição da divisão local do trabalho relativa ao tráfico de drogas vigente em bairros periféricos em Belém do Pará (PA) e destaca suas relações com circuitos ampliados de produção, de circulação e de consumo, onde os jovens se expõem aos riscos gerados pela repressão e pela competição.

Salienta-se ainda a demanda por um know-how técnico-organizacional especializado, de modo que entender o narcotráfico como mera questão de delinquência seria uma simplificação grosseira de sua complexidade enquanto fenômeno social e econômico de ordem transnacional (CHAVEZ ALVAREZ, 1989). No caso específico do Brasil, a vizinhança com países produtores de cocaína e de marijuana, como Colômbia, Bolívia e Paraguai, e a existência de infraestruturas internas de transportes e de comunicações, possibilitam o desenvolvimento de importantes rotas do tráfico em território nacional (ADORNO, 2002).

Essa característica - a de abrigar o trânsito de drogas - faz com que grupos nacionais do narcotráfico permaneçam vinculados às estruturas e organizações nas duas pontas das redes: com produtores e consumidores (MINAYO, 2005). Torna-se evidente, portanto, a contribuição de homens jovens residentes de áreas urbanas brasileiras, não como mentores, investidores ou gestores das atividades ilegais mais relevantes, mas como as componentes mais frágeis e expostas 
à repressão (i)legal violenta, atuando como recurso para a geração de mais-valia em taxas ampliadas.

Seguindo práticas que relacionam o crime às possibilidades de consumo, à elevação do status social e à reafirmação da masculinidade (ZALUAR, 1998), homens jovens, nem sempre os mais destituídos, são atraídos por essa identidade e se incorporam aos grupos criminosos (ZALUAR, 1999), cujo escopo de atuação tende cada vez mais a transcender o âmbito local, tornando-se as maiores vítimas e ao mesmo tempo os maiores perpetradores de homicídio no Brasil (ZALUAR, 2007).

A percepção do avanço da criminalidade como uma tendência mundial não exclui, portanto, a sociedade brasileira, sobretudo porque o país está inserido nas rotas internacionais do tráfico de drogas e de armas, constituindo uma importante base para a expansão da criminalidade violenta, aquela que vitimiza particularmente homens jovens residentes de periferias urbanas (ADORNO, 2002).

Não restam dúvidas de que a pobreza e a iniquidade social tendem a constituir campos altamente propícios à disseminação da criminalidade homicida no Brasil, no entanto, faz-se um alerta para a dimensão sistêmica dessa questão (VELHO, 2000), já que as redes de práticas criminosas, ao incluírem agentes privilegiados, beneficiários de sistemas de impunidade, de sistemas técnicos e do sistema financeiro internacional (BALTAZAR JUNIOR, 2008), são articuladas segundo extensas divisões sócio espaciais do trabalho. Daí a necessidade de serem interpretadas as manifestações predominantes da violência homicida, no Brasil, dentro do contexto do crime transnacional, ou seja, do crime também ele globalizado (ZALUAR, 1996).

Em tais circunstâncias as manifestações espacialmente localizadas da violência juvenil homicida são cada vez mais relevantes no contexto da manutenção de negócios ilícitos de origem transnacional (MINAYO, 2005), reforçando a percepção de que o crime é uma parte importante e em crescimento da economia global, semelhante a outros setores dessa economia, já que utiliza redes similares, se diversifica da mesma maneira, entende o mercado da mesma forma, opera em larga escala e constitui extensas divisões sociais do trabalho (CASTELLS e INCE, 2003: 104).

É importante destacar que os circuitos globais podem ter tanto um caráter mais disseminado, como é o caso das redes informacional e financeira, quanto um caráter segmentado que envolve grupos específicos, como ocorre nas redes ilegais do narcotráfico. Em ambos os casos a escala de atuação é global, mas os recortes privilegiados são distintos, pois, enquanto as redes informacional e financeira envolvem uma clara intenção de expandir ao máximo sua atuação, o 
caráter ilegal dos circuitos do narcotráfico revela uma clandestinidade que se vê retratada em dimensões espacialmente restritas (HAESBART, 1999).

Por isso, mais do que a distinção entre dois circuitos, um global e outro local, o que se deve observar é justamente a vinculação entre eles (HAESBART, 1999), já que a articulação entre atividades distantes, unificadas através de sistemas vigentes em escalas espaciais ampliadas, aparece hoje como uma necessidade rigorosamente imposta a qualquer setor da economia globalizada (BENKO, 2008). Desse modo, a interpretação a respeito dos processos de integração de homens jovens nas redes transnacionais do crime deve ser buscada exatamente na associação entre dinâmicas espacialmente localizadas e elementos estruturais do sistema.

Salienta-se que esse tipo de associação - local/global - é uma característica peculiar da atualidade, daí a necessidade de serem especificadas as características predominantes da violência no período contemporâneo. Reconhece-se, no entanto, que essa perspectiva teórica só encontra relevância quando assumida como uma tendência predominante, não dando conta de casos específicos e isolados, pois, como alertou Wieviorka (1997): não reduzamos a violência exclusivamente às suas dimensões econômica e instrumental, já que ainda hoje suas manifestações seculares continuam a persistir.

\section{CATEGORIZAÇÃO DA VIOLÊNCIA E SUA ARTICULAÇÃO MULTE-ESCALAR NO PERÍODO CONTEMPORÂNEO}

Na tentativa de elucidar as diferentes expressões da violência, para além das amplas definições dadas por autores como Michaud (1986), Arendt (1985), Domenach (1981) e Galtung (1969), considera-se a relevância e a funcionalidade da categorização proposta por Galtung (1990), que define violência 'direta' como a perpetração de atos de agressão física dos quais decorrem traumatismos, lesões ou a morte. Refere-se aos atos violentos diretamente exercidos entre pessoas e grupos de pessoas, sendo o homicídio e o genocídio suas expressões extremas.

Violência 'estrutural' tem seus significados relacionados à vigência de uma ordem social cujo funcionamento implica em oportunidades desiguais para seus membros. Violência 'cultural' faz referência ao elemento simbólico cujo sistema de ideias pode ser utilizado para legitimar a perpetração das outras duas categorias de violência. A ideia que move essa distinção categórica e sua articulação através de um 'triângulo vicioso' é bem simples: violência gera violência (GALTUNG, 1990). 
Salienta-se que com a globalização emergiram formas implacáveis de relações econômicas, justificadas por noções de riqueza, de prosperidade e de (des)equilíbrio macroeconômico às quais todas as economias nacionais são impelidas a se adaptarem. Em tais condições o dinheiro se torna 'onipresente' e a acumulação 'uma meta', lembrando que em âmbito sistêmico a acumulação para alguns significa o endividamento para a maioria (SANTOS, 2000: 55-56).

A necessidade de capitalização, real ou imaginária, conduz à adoção de uma ética da competitividade como regra de convivência entre pessoas, Estados e empresas, que justifica todo o apelo à força e todas as formas perversas de sociabilidade. Os diversos segmentos sociais, de modo a assegurarem sua sobrevivência imediata, tendem a jogarem-se uns contra os outros. Em tais condições evoluímos de situações nas quais a perversidade se manifestava de forma isolada para uma situação na qual a perversidade se instala como sistema, legitimando a preeminência de ações hegemônicas sem responsabilidades perante a coletividade humana, como um convite ao exercício da violência (SANTOS, 2000: 60).

O caráter perverso desse processo se encontra justamente no reforço às tendências de centralização dos recursos e do poder de gestão das mais relevantes esferas da economia e da política, quando o domínio sobre os meios de produção e de divulgação das informações se apresenta como fator básico para a manutenção e o acirramento das desigualdades, tanto entre os países quanto internamente às nações (SANTOS, 1988:17-18).

Nessa linha de raciocínio, assume-se que o entendimento do mundo contemporâneo deve passar necessariamente pelo reconhecimento de um sistema ideológico através do qual todos os aspectos que remetem ao consumo e ao individualismo são intensificados. Já que cada vez menos pessoas ignoram o que o mundo oferece ou promete, como possibilidade, o indivíduo tende à intenção de continuar a consumir se já o fez e de começar a fazê-lo se ainda não o pôde (WIEVIORKA, 1997), atribuindo um papel central ao dinheiro como regulador das vidas individuais (SANTOS, 2000).

De fato, uma revolução nos modelos de consumo chegou também ao Brasil, acompanhada por valores culturais marcados pela carência de limites morais, justificando a resolução de conflitos - comerciais ou interpessoais - através de atos de violência. Tais condições estão atraindo jovens ao comércio de drogas e ao estabelecimento de um estado de guerra em muitas localidades, onde significativas parcelas da população juvenil masculina têm se tornado vulneráveis à vitimização por homicídio (ZALUAR, 2007). 
A violência ligada ao controle e à acumulação de recursos, no entanto, não é arma exclusiva dos desvalidos, já que os agentes mais relevantes da sociedade protagonizam conflitos pelos frutos das atividades econômicas, hoje, em âmbito global (SANTOS, 2000). Por isso, a menção a uma violência de tipo estrutural e, sobretudo, a outra de tipo cultural, comos marcos conceituais relativos a processos de cunho macrossocial, sugere um aumento recente de escala e de intensidade potencializado em acordo com a etapa atual da globalização.

Dentro desses princípios as perspectivas teóricas contemporâneas mais relevantes destacam o reconhecimento das formas predominantes da violência direta como manifestações pontuais de fenômenos globais, pois, ainda que a forma imediata pela qual a violência se expressa seja através de manifestações localizadas, sua noção abrange cada vez mais um conjunto de ações e de situações vigentes em escalas espaciais ampliadas (WIEVIORKA, 1997).

Por isso a análise de um tipo de violência direta que nesse momento específico se torna evidente e particularmente relevante, o homicídio entre homens jovens, tal como se expressa no Brasil, não pode estar reduzida a contextos isolados (MINAYO, 2005), já que ocorre em consonância com a lógica corrente do capital e com a vigência de uma ética pragmática dominante. Mas como avançar desde essa articulação triangular da violência em direção ao reconhecimento de uma articulação de tipo multe-escalar? Desde o ponto de vista teórico-metodológico se reconhece que cada uma das três categorias de violência propostas por Galtung (1990) pode ser analisada segundo escalas particulares, através das quais os fenômenos aos quais correspondam possam ser melhor apreendidos.

Tendo em vista as possibilidades de reflexão que o termo escala adquiri, desde que liberto de sua perspectiva puramente matemática, essa noção ganha contornos no sentido de representar diferentes modos de percepção e de concepção das relações no espaço, em acordo com a extensão territorial e a complexidade dos fenômenos observados, de modo que a escala passa a ser entendida como um problema epistemológico, enquanto definidora de espaços de pertinência e de artifícios analíticos que dão visibilidade aos problemas de interesse (CASTRO, 1995).

A mudança da escala corresponde a uma mudança na dimensão conceitual que define o nível espacial mais adequado para uma determinada análise. Ademais, no plano do conhecimento não há nível espacial privilegiado, já que nenhum deles é por si só suficiente, pois, quanto mais a prática é global e atinge localidades espalhadas pelo planeta, mais ela deve ser referida a um saber abstrato capaz de articular problemas de ordem planetária às dinâmicas da ordem local (LACOSTE, 1976).

Revista de Direito da Cidade, vol. 08, no 3. ISSN 2317-7721 pp.970-992 
Partindo do ponto de vista que considera a necessidade de análises multe-escalares para a apreensão de fenômenos contemporâneos, assume-se que as expressões da violência cultural tendem a serem manifestas em escalas ampliadas de análise, ao justificarem a expansão de formas perversas de realização da vida soacial e econômica, expressas no espaço através de manifestações particulares da violência estrutural e da violência direta.

A imposição de uma racionalidade econômica dominante que teoricamente alcança a todos os subespaços do planeta tende a estimular respostas particulares, em acordo com os diversos modos das racionalidades próprias de cada território e de cada lugar, em um processo que caracteriza o sentido das diferenciações sócio espaciais no atual período, como reflexos da espacialização heterogênea e desigual de processos globais (SANTOS, 1996).

Assume-se, portanto, a manifestação das três categorias de violência propostas por Galtung (1990) segundo três níveis espaciais distintos e vigentes em acordo com uma interação triangular e multe-escalar:

1. Violência cultural: perpetrada em escala global pelos agentes hegemônicos da política, da cultura e da economia, como os Estados nacionais, as organizações supranacionais, as grandes redes de informação midiática e as empresas transnacionais. Expressa pelo uso corporativo dos recursos técnicos, humanos, naturais e financeiros presentes nos territórios e nos lugares. Caracterizada pelo desenvolvimento de um sistema financeiro global e pela expansão de uma ética pragmática dominante funcionais à lógica capitalista;

2. Violência estrutural: manifestação de processos de relativa exclusão/inclusão social e econômica, expressa pela seletividade no uso dos territórios nacionais, pela distribuição desigual das infraestruturas e dos serviços urbanos e pelas decorrentes divisões sociais e espaciais do trabalho. Orientada no sentido do aprofundamento das desigualdades quanto ao acesso aos principais benefícios da urbanização e do crescimento econômico, entre os países e internamente aos países;

3. Violência direta: descreve atos de violência perpetrados de pessoa para pessoa, no sentido do exercício da agressão física ou verbal, a um indivíduo ou a um coletivo de indivíduos, indiferentemente do método ou do instrumento utilizado. Suas manifestações extremas são o homicídio e o genocídio, expressos em decorrência de conflitos de caráter pessoal ou comercial, resolvidos na ordem do cotidiano e da co-presença, ou seja, na escala do lugar. Perante esse cenário assume-se que a existência de um ato subjetivo na entrada de qualquer pessoa no mundo do crime não descarta as maiores potencialidades representadas por 
conjunturas onde o desemprego e o sentimento de exclusão atingem mais extensos segmentos da população (MINAYO, 2005; WIEVIORKA, 1997).

A configuração sistêmica, por sua vez, proporciona condições para que conjunturas desfavoráveis de relativa exclusão social e econômica sejam contraditoriamente incluídas na ordem do funcionamento global, de maneira que não desprezíveis volumes de jovens são utilizados como recurso para a expansão de circuitos transnacionais do crime, processo que apresenta como consequência mais perversa e evidente a elevação local das taxas de homicídio, conforme há décadas se observa nas periferias urbanas brasileiras.

\section{CONSIDERAÇÕES FINAIS}

Se a violência tem o poder de dramatizar situações trazendo-as à atenção do público (ARENDT, 1985) é importante reconhecer que as explicações acerca da disseminação do homicídio juvenil masculino, no Brasil urbano contemporâneo, não podem estar limitadas a questões circunscritas aos subespaços onde habitualmente se manifesta, de modo que o enfrentamento dessa problemática demanda perspectivas relativamente complexas, que considerem as relações entre a existência de significativos volumes de jovens que sobrevivem em situações de evidente violência - cultural e estrutural - e seus maiores potenciais de integração ao crime nas cidades e regiões metropolitanas brasileiras.

A construção teórica que vislumbra a expansão do homicídio juvenil masculino através de uma interação triangular e de tipo multe-escalar com outras duas categorias de violência revela que enquanto a atenção da opinião pública e a ação dos setores responsáveis pela segurança pública estão voltadas quase que exclusivamente à condenação da violência direta, na maior parte das vezes são desconsiderados os processos que estão na base da disseminação desse fenômeno, ou seja, a violência cultural e a violência estrutural.

Conclui-se que o processo de elevação do homicídio juvenil masculino no Brasil não deve ser diretamente relacionado aos contextos espacialmente localizados de relativa pobreza e exclusão, já que deriva de relações muito mais amplas que possibilitam a utilização de não desprezíveis contingentes de homens jovens como recurso para a expansão de economias transnacionais do crime.

Considera-se, portanto, que as estratégias para a mitigação dessa catástrofe que há décadas assola a sociedade brasileira - a perda anual sistemática de um significativo volume de homens jovens por homicídio - não devem ser desenvolvidas exclusivamente a partir da repressão 
aos segmentos populacionais que sofrem de maneira mais intensa as diversas categorias de violência, já que para chegar a melhores resultados devem levar em consideração a dimensão sistêmica e multe-escalar desse fenômeno.

\section{BIBLIOGRAFIA}

ADORNO, Sérgio (2002). Exclusão socioeconômica e violência urbana. Sociologias, Porto Alegre, v. 4, n. 8, p. 84-135, jul./dez. 2002.

AIDAR, Tirza. A face perversa da cidade: configuração sócio-espacial das mortes violentas em Campinas nos anos 90. 2003. 122p. Tese (Doutorado em Demografia) - Programa de Doutorado em Demografia da Universidade Estadual de Campinas, Campinas-SP.

ANTUNES, Ricardo. Dimensões da precarização estrutural do trabalho. In: DRUCK, Graça; FRANCO, Tânia (Org.) A perda da razão social do trabalho: terceirização e precarização. São Paulo: Boitempo, 2007, p. 13-22.

ARENDT, Hannah (1985). Da violência. Brasília: Editora Universidade de Brasília, 1985, 71 p.

BALTAZAR JUNIOR, José P. Crime Organizado. Caderno de Direito Penal, Porto Alegre: TRF, módulo 4, 2008, p. 7-66. Disponível em:<http://www2.trf4.jus.br/trf4/upload/editor/rom_BALTAZAR_JUNIOR.pdf>. Acesso em: 03 de mar. de 2012.

BATISTA, Vera M. Difíceis ganhos fáceis: drogas e juventude pobre no Rio de Janeiro. Rio de Janeiro: Instituto Carioca de Criminologia, 2003, 88 p.

BENKO, Georges. A recomposição dos espaços. Interações, Campo Grande, v. 1, n. 2, p. 7-12, mar. de 2001.

BENKO, Georges; PECQUEUR, Bernard (2001). Os recursos de territórios e os territórios de recursos. Geosul, Florianópolis, v.16, n.32, p. 31-50, jul./dez. 2001.

BERCOVICH, Alícia; DELLASOPPA, Emilio; ARRIAGA, Eduardo. J'adjunte, mais je ne corrige pas: jovens, violência e demografia no Brasil. Algumas reflexões a partir dos indicadores de violência. In: BERQUÓ, Elza. Jovens acontecendo na trilha das políticas públicas. Brasília: IPEA/CNPD, 1998, p. 293-363.

BRAUDEL, Fernand. Os jogos das trocas. Civilização material, economia e capitalismo: séculos XVXVIII. Tomo II. Lisboa-Rio de Janeiro: Edições Cosmos, 1985, 628 p.

CAMPOS, Marcelo da Silveira; VALENTE, Rodolfo de Almeida. O julgamento do recurso extraordinário 635.659: pelo fim da guerra as drogas. Boletim IBCCRIM, São Paulo, v. 20, Ed. Especial, p. p. 02-04, out. de 2012. 
CANIATO, A. M. P. Violências e subjetividades: o indivíduo contemporâneo. Psicologia \& Sociedade, Belo Horizonte, v. 20, n. 1, p. 16-32, 2008.

CARVALHO, I. L. de. O direito penal como instrumento inibidor da violência. Revista de Informação Legislativa, Brasília, v. 33, n. 131, p. 123-128, 1996.

CASTELLS, Manuel. A Era da Informação: Economia, sociedade e cultura, vol. III - O fim do milénio, Lisboa: Fundação Gabuste Gulbenkain, 2003, p. 476.

CASTELLS, Manuel; INCE, Martin. Conversas com Manuel Castells. Porto: Campo das Letras, 2003, p. 233.

CASTRO, I. E. de. O problema da escala. In CASTRO, I.E. de; GOMES, P.C. da C.; CORRÊA, R.L. (Orgs.) Geografia: conceitos e temas. Rio de Janeiro: Bertrand Brasil, 1995, p. 238.

CERQUEIRA, Daniel; MOURA, Rodrigo L. de. Custo da Juventude Perdida no Brasil. In: SEMINÁRIO JUVENTUDE E RISCO: PERDAS E GANHOS SOCIAIS NA CRISTA DA POPULAÇÃO JOVEM. Rio de Janeiro, Rio de Janeiro: IPEA, 2013.

CHAVEZ ALVAREZ, Manuel Gonzalo. Narcotráfico: um novo item nas relações entre os EUA e a América Latina. Política e Estratégia, São Paulo, v. 7, n.1, p. 40-52, mar./abr. 1989.

COCCO, Giuseppe. Entre a universalização da guerra e universalização dos direitos. In: PACHECO, Anelise; VAZ, Paulo. Vozes do milênio: para pensar a globalização, Rio de Janeiro: Griphus Editor, 2002, p. 194.

COSTA, P. Tamanho do crime. Revista Consultor Jurídico. São Paulo, 26 ago. de 2007. Disponível em: <http://www.conjur.com.br/2007ago26/direito_penal_nao_resolve_violencia_nem_criminalidade >. Acesso em: 27/06/2016.

COUTO, Aiala C. de O. Do global ao local: a geografia do narcotráfico na periferia de Belém. Cadernos de Segurança Pública. Rio de Janeiro, v. 4, n. 3, p. 2-13, maio de 2012.

DELLASOPA, E.; BERCOVICH, A. M.; ARRIAGA, E. Violência direitos civis e demografia no Brasil na década de 80: o caso da Área Metropolitana do Rio de Janeiro. Revista Brasileira de Ciências Sociais, v. 14, n. 39, p. 155-176, fev. de 1999.

DOMENACH, Jean M. La violência. In: Unesco (Org.) La violencia y sus causas, Nova York: Editorial Unesco, 1981, p. 31-46.

DOWDNEY, Luke. Nem guerra nem paz: comparações internacionais de crianças e jovens em violência armada organizada. Rio de Janeiro: Editora 7 letras, 2005, p. 378.

DUFFIELD, Mark. Global governance and the new wars: the merging of development and security. London: Zed Books, 2001, p. 293.

GALTUNG, Johan. Cultural violence. Journal of peace research, Oslo, v. 27, n. 3, p. 291-305, 1990. 
Violence, peace, and peace research. Journal of peace research, Oslo, v. 6, n. 3, p. 167-191, 1969.

GIIS. Guns and the city. Cambridge: University Press, 2006.

HAESBART, Rogério. Região, diversidade territorial e globalização. GEOgraphia, Rio de Janeiro, v. 1, n. 1, p. 15-39, 1999.

HIRATA, Helena. Salariado, precariedade, exclusão. Trabalho e relações sociais de sexo-gênero: uma perspectiva internacional. In: OLIVEIRA, M. C. (Org.) Demografia da exclusão social. Campinas: Editora da Unicamp, 2001, p. 105-118.

LACOSTE, Yves. La géographie, ça sert, d’abord, à faire la guerre. Paris: Maspero, 1976, p. 184.

LOPES, C.; SACHS, I.; DOWBOR, L. Crises e oportunidades em tempos de mudança. In: DOWBOR, L.; SACHS, I. e LOPES, C. (Orgs.). Riscos e oportunidades em tempos de mudança. São Paulo: Editora e Livraria Instituto Paulo Freire, 2010, p. 133-154.

LOZADA, E. M. K. de; MATHIAS, T. A. de F.; ANDRADE, S. M.; AIDAR, T. (2009). Informações sobre mortalidade por causas externas e eventos de intenção indeterminada, Paraná, Brasil, 1979 a 2005. Cadernos de Saúde Pública. Rio de Janeiro, v. 25, n. 1, p. 223-228, 2009.

MANETTA, A.; ALVES, J. E. D. Óbitos violentos e inflexão precoce na razão de sexo: Argentina e Brasil (2001-2011). Revista Latinoamericana de Población, Montevidéu, n. 17, p. 83-106, 2015.

MICHAUD, Yves-Alain (1973). La violence. Paris: Presses Universitaires de France, 1986, p. 336.

MINAYO, M. C. de S. Seis características das mortes violentas no Brasil. Revista Brasileira de Estudos da População, Rio de Janeiro, v. 26, n. 1, p. 135-140, 2009.

Violência um problema para a saúde dos brasileiros. In: Brasil/ Ministério da Saúde, Impacto da violência na saúde dos brasileiros. Brasília: Ministério da Saúde, 2005, p. 9-33.

OLIVEIRA, M. C.; PINTO, L. G. Exclusão social e demografia: elementos para uma agenda. In: OLIVEIRA, M. C. (Org.) Demografia da exclusão social: temas e abordagens. Campinas: Editora da Unicamp/Nepo, 2001, p. 12-58.

PIKETTY, Thomas. Le capital au XXle siècle. Paris: Seuil, 2013, p. 970.

PNUD. Relatório do Desenvolvimento Humano 2005, Nova York: ONU, 2005, p. 344.

RIBEIRO, Ana C. T. Ação e seleção social: impulsos globais em contextos metropolitanos. In: CASTRO, Iná Elias de (Org.). Redescobrindo o Brasil: 500 anos depois. Rio de Janeiro: Bertrand Brasil, 2000, p. 291-300.

SACHS, Ignacy. A vitalidade do pensamento de Marx. Estudos Avançados, São Paulo, v. 12, n. 34, p. 65-66, set./dez. de 1998. 
SANTOS, José V. T. dos. Por uma sociologia da conflitualidade. In: SANTOS, J. T. V. dos (Org.) Violências no tempo da globalização. São Paulo: Hucitec, 1999, p. 11-43.

SANTOS, Milton. O espaço dividido: os dois circuitos da economia urbana dos países subdesenvolvidos. Rio de Janeiro: Francisco Alves, 1979.

A natureza do espaço: espaço e tempo, razão e emoção. São Paulo: Hucitec, 1996, p. 308.

Metamorfoses do espaço habitado: fundamentos teóricos e metodológicos da geografia. São Paulo: Hucitec, 1988, p. 136.

Por uma outra globalização: do pensamento único á consciência universal. Rio de Janeiro: Record, 2000, p. 236.

SARAMAGO, José. Levantados do chão. Lisboa: Editora Caminho, 1980.

SASSEN, Saskia. The Global City: New York, London, Tokyo. Princeton: Princeton University Press, 1991.

SOARES, L. E. Segurança pública: presente e futuro. Estudos Avançados, São Paulo, v. 20, n. 56, p. 91-106, 2006.

SOUZA, D. P. O. de; ARECO, K.N.; SILVEIRA FILHO, D. X. da. Álcool e alcoolismo entre adolescentes da rede estadual de ensino de Cuiabá, Mato Grosso. Revista de Saúde Pública, São Paulo, v. 39, n. 4, p. 585-592, 2005.

SZWARCWALD, C. L.; BASTOS, F. I.; ESTEVES, M. A. P.; ANDRADE, C. L. T. de; PAES, M. S.; MEDICI, E. V.; DERRICO; M. Desigualdade de renda e situação de saúde: o caso do Rio de Janeiro. Cadernos de Saúde Pública, Rio de Janeiro, v. 15, p. 15-28, 1999.

VEEN, Hans T. V. der. The International Drug Complex: When the visible hand of crime fractures the strong arm of the law. [em linha]. European University Institute, 1999. < http://www.cedrouva.org/lib/veen.complex.html >.[02/02/2012].

VEGA, Carlos A.; KRUIJT, D. Viejos y nuevos actores violentos en América Latina: temas y problemas. Foro Internacional, Ciudad de México, v. 47, n. 3, p. 485-516, 2007.

VELHO, Gilberto. O desafio da violência. Estudos Avançados, São Paulo, v. 14, n.39, p. 56-60, 2000.

WAISELFISZ, J. J. Mapa da Violência 2010: anatomia dos homicídios no Brasil. São Paulo: Instituto Sangari, 2010, p. 151.

Mapa da Violência 2011: os jovens do Brasil. São Paulo: Instituto Sangari, 2011, p. 163.

Mapa da violência 2013: homicídios e juventude no Brasil. São Paulo: Instituto Sangari, 2013, p. 100.

Mapa da violência 2014: homicídios e juventude no Brasil. Atualização 15 a 29 anos. São Paulo: Instituto Sangari, 2014b, p. 144.

Mapa da violência 2014: os jovens do Brasil. São Paulo: Instituto Sangari, 2014a, p. 190.

Mapa da violência 2015: adolescentes de 16 e 17 anos no Brasil. São Paulo: Instituto Sangari, 2015a, p. 72.

Mapa da violência 2015: mortes matadas por armas de fogo. São Paulo: Instituto Sangari, 2015b, p. 112. 
Mapa da Violência: os jovens da América Latina. São Paulo: Instituto Sangari, 2008, p. 120.

WIEVIORKA, Michel. The new paradigm of violence. Tempo social, São Paulo, v. 9, n. 1, p. 5-41, 1997.

ZALUAR, Alba. A globalização do crime e os limites da explicação local. In VELHO, Gilberto; ALVITO, Marcos (Orgs.). Cidadania e violência. Rio de Janeiro: Editora FGV/UFRJ, 1996, p. 49-69.

Democratização inacabada: fracasso da segurança pública. Estudos Avançados, São Paulo, v. 21, n. 61, p. 31-49, 2007.

Para não dizer que não falei de samba: os enigmas da violência no Brasil. In: SCHWARTZ, L. (Org.). História da vida privada no Brasil: contrastes da intimidade - v. IV. São Paulo: Companhia das Letras, 1998.

Um debate disperso: violência e crime no Brasil da redemocratização. São Paulo em perspectiva, São Paulo, v. 13, n. 3, p. 3-17, 1999.

Trabalho enviado em 14 de abril de 2016.

Aceito em 03 de julho de 2016. 